\title{
A MODEL FOR UNIVERSITY SEMINARS HELD IN COMPANIES
}

A case study

\author{
Peeter Normak \\ Tallinn Pedagogical University, Tallinn, Estonia \\ pnormak@iatpu.ee, http://www.tpu.ee/ pnormak
}

\begin{abstract}
The paper discusses a model for university seminars that take place in ICT companies or IT departments of companies. The presentation examines the main implications in the light of three years of experience in running such seminars.
\end{abstract}

Keywords: Enterprise-based seminar, curriculum development, work preparedness.

\section{INTRODUCTION}

Although there seems to be a consensus among the main actors that experts from companies should be invited to take part in development and running of study programs, no big progress can be observed. Therefore, new forms of university-enterprise cooperation should be introduced tuned to local conditions. For example, in a small country like Estonia, the following important observations can be made:

1. The universities running ICT-curricula are preparing specialists for different ICT-sectors (Tallinn Pedagogical University (TPU) mainly for the educational sector).

2. The student intake in ICT specialties in universities was recently considerably increased and new curricula were started. Most of the students are already employed before university graduation.

3. The interest of companies in producing software for different sectors varies considerably. For example, because of the small market and lack 
of finance there is almost no interest in producing educational software for schools.

4. Most ICT companies are working in a project-based mode. This means that they do not have far-reaching professional development plans and clear visions about personnel needs in the future.

All this has the consequence that without any special effort the companies are interested in universities only occasionally. In the following we will discuss a model of university-enterprise joint seminars that turned out to be extremely successful from the point of view of all the main actors: students, university teachers and the participating industry people.

\section{BACKGROUND}

Students must make an important decision when they choose the company for practical placement. The feedback information from students and graduates indicated that their expectations toward the company's profile they started to work in, as well as the expectations of companies towards the competence of graduates were in many cases only partly/partially met. A small empirical study performed in 1999 and 2000 with a sample size of about thirty persons - interviews with the graduates as well with some students - revealed some difficulties they had in starting their professional activities:

- University graduates do not have an adequate overview of different ICT companies, their profiles, priorities, needs, salary levels etc. Consequently, their first job is determined more or less opportunistically; in many cases a recent graduate moves after a relatively short period of work to another company.

- Graduates are uncertain in applying to a company; they do not know how to behave, what professional competencies and personality properties are preferable, and most importantly whether the organizational culture corresponds to the applicants' wishes and habits.

- The work in a company will in most cases start with a relatively long study period, which is sometimes devoted to topics completely missing in university curricula.

\section{THE MODEL}

The aim was to develop a model for seminars taking place in different companies that will give the students a possibility to understand and assess 
basic activities of the companies: institutional management, ICT production, marketing, strategic planning and innovation, personnel policy etc. Organizational details of these seminars can be found in Normak (2003). Here, only the main features of these seminars are described:

- The academic tutor compose a list of companies and makes arrangements with them. The seminars take place once a week during one semester and last for 90 minutes.

- The seminars are planned during a preparatory meeting with the students. For each seminar, a discussion group of at least three students is formed. The main task of discussion groups is to study the company before the seminar and to prepare discussions for the seminar.

- Before each seminar, the academic tutor informs the receiving officers of the company about the aims of the seminar; the company should be sent the syllabus for the seminar (containing the possible list of problems that could be discussed), and the university curriculum.

- The students are accompanied by their academic tutor and/or by the head of the curriculum.

- The seminar should be led from the company side by a key person (- in fact in about $80 \%$ of cases the students were met by the heads of the companies/ICT departments).

- At the end of semester, every student writes an analytical report. The reports should contain, in addition to a general analysis of the ICT domain in Estonia, a discussion of the companies visited during the seminars and recommendations for changes for seminars in subsequent years.

- Based on the quality of preparation for the seminars, the level of participation in discussions, and on the quality of the analytical report, every student will be assigned a mark (0-5, with 0 indicating not qualified).

- Every qualified student is awarded three ECTS credits.

\section{EVALUATION}

During the last three years, three student groups (consisting in average of 16 students) had seminars in ICT companies (35 seminars) and ICT departments of companies ( 9 seminars). For determining a long-term impact of the seminars the former students were asked to fill in a questionnaire one to three years after graduation. As the university does not keep regular contacts with the graduates only about $50 \%$ of them did receive the questionnaires; 16 were returned. The questions were divided into two groups, eight questions each. 
In the first group questions and answers were the following:

1. Did you have a permanent job during the period of time the seminars took place?

Two third of the students did have a permanent job.

2. Did the seminars help you to find a company for practical placement? Only one student found a placement in a company that was visited.

3. Did the seminars motivate you to change the company you worked in?

In two cases the students moved to a company visited during the seminars.

4. What could be changed in the format of the seminars?

There were only few suggestions like "Companies should not use the seminars for promotion of their products" or "There should be more discussions about work conditions and work content, and less about the company's history."

5. What were the most valuable outcomes from the seminars for you?

The outcomes most frequently mentioned were as follows:

- Understanding what are the main problems of ICTcompanies.Generalized view about the ICT market and its development trends.

- Motivation to analyze personal career possibilities.

- Overview of working conditions and needs in personnel.Understanding that for success permanent, learning is necessary.Information on how companies evaluate their people.The visions company people had concerning future developments in the IT sector.Understanding that performance of different companies can differ enormously. What kind of knowledge obtained from the seminars turned out to be useful for you?

Most frequent answers were the following:

- Knowledge of which companies are trustful and which not.Ability to recognize advanced as well as weak

companies.Understanding that employment interviews should be prepared.Knowledge of competences mostly needed in companies.Personal contacts with company people.Understanding the value systems of company people.Possibility to compare work conditions in different companies with those in the company I am working in.Understanding that the image and the actual level of a company should not necessarily be positively correlated.Did the seminars change your attitude towards the university studies? 
About half of the students indicated that the seminars helped them to perform their studies in a more focused manner.

8. How you rate the necessity of the seminars on the scale from 1 (absolutely not necessary) to 10 (absolutely necessary).

The average score was 8,8 . The average score could even be higher if some students did not score every single company separately.

The questions in the second group asked students to assess the level of knowledge on certain aspects of ICT-companies before and after the seminars, on the scale from 1 (absolutely no knowledge) to 10 (excellent knowledge). The questions and average marks were the following:

1. General knowledge about the activities of Estonian ICT-companies $(4,2$ and 7,3 , respectively).

2. Areas of activities $(4,7$ and 7,2$)$.

3. Knowledge and skills expected from the employees $(4,1$ and 6,5$)$.

4. Work methods and tools $(3,4$ and 5,9$)$.

5. Organizational and work culture $(3,3$ and 6,5$)$.

6. Personnel policy, employment possibilities $(3,4$ and 5,8$)$.

7. Salary levels $(4,2$ and 5,1$)$.

8. Difficulties and problems $(3,6$ and 6,2$)$.

As we see the biggest differences in average marks are by questions 1 and 5 , the smallest difference by question 7 . This is quite understandable as the company people were relatively reluctant to discuss the salary levels, even in a relatively general manner. In personal advancement of students (measured by difference of total score after and before the seminars) the students formed two groups of an equal size: one consisting of those having total advancement between 23 and 31 and another of those with total advancement between 7 and 16.

\section{IMPLICATIONS AND CONCLUSIONS}

The experience obtained from planning and running the seminars, and from analytical reports and post-seminar activities allow us to formulate some general conclusions.

1. The companies are interested in this kind of seminars; only in two cases were the initially planned companies replaced because the companies were not cooperative enough (no company refused directly). Very often the company people were surprised about the amount of information the students found out about the company. 
2. The level of preparation for the seminar and actual running from the company side varied considerably, from very good presentations and tours, distribution of information materials and souvenirs, refreshments etc. to companies that did not do any preparation at all.

3. The companies usually did not keep to the proposed topics for discussion, and discussions evolved in a natural way (this was appreciated by students). Some presenters did pay more attention to the general problems - how to start a successful company, the role of education and personal qualities etc. - some did stick to problems of the company currently under discussion.

4. The company people are not interested in analyzing the university curricula: a fact that was disliked by many students. The main recommendations from company people were that university curricula should: a) develop team-working and social skills; b) teach fundamental ideas as concrete knowledge about specific problems can be taught at the working place; c) ensure foreign language skills (English and sometimes Russian).

5. The students identified in their analytical reports the main problems in ICT development in Estonia at the moment as the following: a) lack of skilled ICT specialists and project managers; b) too big a percentage of very small ICT companies who push the prices down and provide insufficient quality level; c) the Estonian market is too small for effective development of ICT companies.

6. The students considered the seminars extremely useful and interesting. There was no consensus about recommendations for the future (example: whether to visit for comparison purposes some weak companies as well).

7. The students are interested to meet with mid-level and lower-level employees of companies as well; this would give a broader view about the company rather than discussions solely with top managers.

8. The seminar should be kept within a time limit; very often there were some students interested in a particular company and eager to hold long discussions.

9. For comparison purposes, quality indicators should be set so that students could evaluate the companies.

10. The seminars deepened the involvement of companies in the university's academic life. For example, the IT department of the second biggest bank of Estonia became a strategic partner in running the IT-management master's program; highly qualified professionals were included in university graduation committees and invited to present lectures devoted to the case studies arising from their activities.

11. The seminars in many cases influenced the topics for graduation papers. 
12. The seminars allow some generalizations concerning the main processes used in the companies. For example, only very few companies are using some software development models or taking into account maturity models.

13. A discrepancy between beliefs and real practice was observed. In many cases the company people were very positive about different practices but did not use these themselves (for example, usage of pair programming).

\section{REFERENCES}

Normak, P. (2003) University-enterprise joint seminars as tools for preparing students for the world of work: a case study from Estonia, Industry and Higher Education Vol 17, Number 2, April 2003, pp. 103-109. 